\title{
RELEASE MECHANISM OF AN AVALANCHE ON A SLOPE COVERED WITH BAMBOO BUSHES
}

\author{
by
}

\section{YASOICHI ENDO}

Institute of Low Temperature Science, Hokkaido University, Sapporo, Japan 060

\section{ABSTRACT}

The glide of a snow cover on a slope covered with bamboo bushes was simulated so that the bushes' resistance to glide was quantitatively related to the glide distance and speed. In one case their stalks and leaves were kept in the snow without falling down, in a second case they fell down and lay under the snow. Using the relations obtained, a description was given as to the behavior of a snow cover on a uniform slope as well as the distribution of stress and glide speed immediately before crack formation. Then, a criterion of crack formation was given in terms of glide speed.

\section{INTRODUCTION}

Avalanches usually occur in Japan on slopes covered with bamboo bushes. When such a slope is examined, it is found that slope friction is composed of resistance of the bushes' stalks and leaves, both in the snow and underneath it (Endo 1983). This paper examines characteristic behavior of the snow cover, due to their resistance, explaining that (1) the glide speed of the snow cover increases rapidly after the glide distance has reached 0.1 to $0.2 \mathrm{~m}$, and (2) a crack is usually formed near the upstream boundary of a region whose glide distance has exceeded the length of the bamboo bushes.

\section{RESISTANCE OF TWO GROUPS OF BAMBOO BUSHES}

The resistance of bamboo bushes to the glide on a slope was measured by simulating the glide in a cold room. In one case the bushes were kept in the snow, and in the second case they lay under it. The first case was simulated by pulling a bamboo 1 in length, out of a block of snow; then the pulling force, the pulling speed and the pulled distance represented the resistance $P$, the glide speed $U$ and the glide distance $D$, respectively. As a result the following approximate relation was obtained:

$$
P=(U / A)^{1 / 3} \exp (-b D) \text { for } D<l ; P=0 \text { for } D \geqslant 1
$$

where $\mathrm{b}$ and $\mathrm{A}$ are the constants. The value of $\mathrm{b}$ is about $2.8 \mathrm{~m}^{-1}$, independent of temperature, but $\mathrm{A}$ is sensitive to it, being of the order of $10^{-8} \mathrm{~m} \mathrm{~d}^{-1} \mathrm{~N}^{-3}$ at $0^{\circ} \mathrm{C}$ and $10^{-10}$ $\mathrm{m} \mathrm{d}^{-1} \mathrm{~N}^{-3}$ at $-1^{\circ} \mathrm{C}$.

The second case was simulated by pulling a snow block with a free water content of 1 to $2 \%$ at a constant speed ranging from 0.01 to $4.00 \mathrm{~m} \mathrm{~d}^{-1}$ over the base which was entirely covered with bamboos lying flat parallel to the direction of the pull. The resultant relation is:

$$
\tau / \sigma=0.45(U / B)^{1 / 3} \text { for } U<B ; \tau / \sigma=0.45 \text { for } U \geqslant B
$$

where $\tau$ is the resistance of fallen bamboos per unit basal area, $\sigma$ is a normal stress on the base and the value of $B$ is about $0.22 \mathrm{~m} \mathrm{~d}^{-1}$

\section{SNOW GLIDE ON A UNIFORM SLOPE}

Consider a snow cover on a uniform slope, assuming that the slope is covered entirely with fallen bamboos and that some bamboos, $\mathrm{n}$ in number per unit basal area, have not fallen down, but kept standing in the snow. Then the equilibirium condition is

$$
\mathrm{h} \rho \sin \theta=\mathrm{nP}+\mathrm{T}
$$

where $\mathrm{h}$ is the snow depth, $\rho$ the snow density and $\theta$ the slope angle. For $D \geqslant 1(P=0)$, it follows from Equations (2) and (3) that, when $\theta \leqslant \arctan 0.45$, an equilibrium speed is given by $U=B(\tan \theta / 0.45)^{3}$, whereas, when $\theta>\arctan$ 0.45 , the condition is unsatisfied, ie the snow cover is unstable.

For $\mathrm{D}<1$, the substitution of (1) and (2) in (3) gives a differential equation of $D$, because $U=d D / d t$. Its solutions for an initial value of $D=0$ at $t=0$ were shown by solid lines in Figure 1 with the parameter $n$. The following values, which are representative of the field conditions, were used in the integration: $1=1 \mathrm{~m} ; \mathrm{h}=1 \mathrm{~m}$; $\rho=300 \mathrm{~kg} \mathrm{~m}{ }^{-3} ; \theta=30^{\circ} ; \mathrm{B}=0.22 \mathrm{~m} \mathrm{~d}^{-1} ; \mathrm{b}=2.8 \mathrm{~m}^{-1}$ and $\mathrm{A}=10^{-10} \mathrm{~m} \mathrm{~d}^{-1} \mathrm{~N}^{-3}$. The curves of the solutions resemble the observed curves shown by broken lines (Endo 1983). According to Figure 1, the snow cover containing 5 bamboos $/ \mathrm{m}^{2}$ cannot become unstable (D $\geqslant 1 \mathrm{~m}$ ) for more than 3 months.

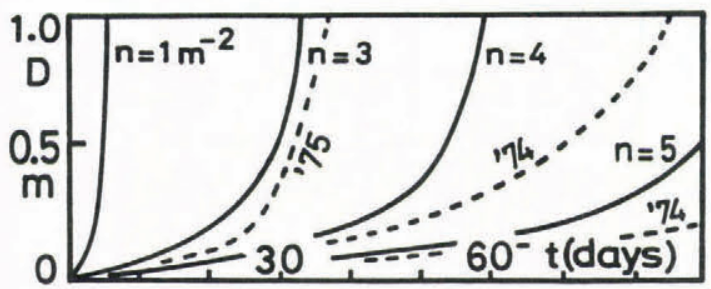

Fig.1. Curves of glide distance $D$ against time $t$ $-1=$ calculated curve; $---=$ observed curve.

\section{DISTRIBUTION OF STRESS AND GLIDE SPEED}

Let us examine the formation of a crack by considering a simple model shown in Figure 2, where on the part of the slope denoted smooth $(0 \leqslant x \leqslant L)$ all bamboos have fallen down $(P=0)$, while on the parts denoted rough $(\mathrm{x}<0$ and $\mathrm{L}<\mathrm{x}$ ) some bamboos remain in snow $(P>0)$. In this model, the upstream part of the snow cover $\left(0 \leqslant x \leqslant L_{0}\right)$ must be elongated and the downstream part $\left(\mathrm{L}_{0} \leqslant \mathrm{x} \leqslant \mathrm{L}\right)$ compressed in the $\mathrm{x}$-direction.

Now, assume that the snow density $\rho$ is uniform and the longitudinal stress and strain-rate, $\sigma_{\mathrm{x}}$ and $\dot{\epsilon}_{\mathrm{x}}$, hardly vary with the depth, so that $\dot{\epsilon}_{\mathrm{x}} \approx \mathrm{dU} / \mathrm{dx}$.

The strain rate is related to the stress by

$$
\begin{array}{r}
\dot{\epsilon}_{\mathrm{x}}=\left(1 / \eta_{\mathrm{x}}\right) \sigma_{\mathrm{x}}-\left(v_{\mathrm{y}} / \eta_{\mathrm{y}}\right) \sigma_{\mathrm{y}}-\left(v_{\mathrm{z}} / \eta_{\mathrm{z}}\right) \sigma_{\mathrm{z}}, \\
\dot{\epsilon}_{\mathrm{y}}=\cdots, \\
\dot{\epsilon}_{\mathrm{z}}=\cdots
\end{array}
$$

According to Shinojima (1967), Poisson's ratio $v$ is 0.5 if $\sigma$

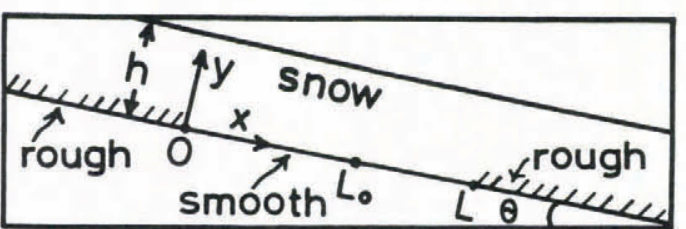

Fig.2. Slope geometry prior to crack formation. 
is tensile and it is zero if compressive; and the coefficient of viscosity $\eta=\eta_{e}$ if $\sigma$ is tensile and $\eta=\eta_{c}$ if compressive. As $\sigma_{\mathrm{y}}$ is compressive and $\dot{\boldsymbol{\epsilon}}_{\mathrm{z}}$ is zero, we have from (4)

$$
\left(3 \sigma_{\mathrm{x}}\right) /\left(4 \pi_{\mathrm{e}}\right)=\dot{\epsilon}_{\mathrm{x}} \approx \mathrm{dU} / \mathrm{dx} \text { for } 0 \leqslant \mathrm{x} \leqslant \mathrm{L}_{0}
$$

Now, it follows from (5) that the equilibrium condition of snow

$$
h\left(d \sigma_{x} / d x\right)-\tau(U)+h p \sin \theta=0
$$

becomes a differential equation of $U$. The boundary conditions are $\mathrm{U}=\mathrm{U}_{\mathrm{o}}$ at $\mathrm{x}=0$ and $\dot{\boldsymbol{\epsilon}}_{\mathrm{x}}=0$, $\mathrm{i}$ e $\mathrm{dU} / \mathrm{dx}=$ 0 at $\mathrm{x}=\mathrm{L}_{0}$.

When $\tau(U)$ is substituted by

$\tau / \sigma=\mu+\lambda U$, where $\mu=0.2$ and $\lambda=1.0 \mathrm{~d} \mathrm{~m}^{-1}$

which is a good approximation of (2) for $0.01<U<0.3$ $\mathrm{m} \mathrm{d}^{-1}$, the solution has the following analytical form:

$$
U=q / \omega^{2}-\left(q / \omega^{2}-U_{0}\right) \cosh \left\{\omega\left(L_{0}-x\right)\right\} / \cosh \left(\omega L_{0}\right)
$$

where

$$
\omega^{2}=\left(3 \lambda \rho / 4 \pi_{e}\right) \cos \theta \text { and } q=\left(3 \rho / 4 \eta_{e}\right)(\sin \theta-\mu \cos \theta) .
$$

Then from (5) and (8)

$$
\sigma_{x}=\left(4 n_{e^{\omega / 3}}\right)\left(q / \omega^{2}-U_{0}\right) \sinh \left\{\omega\left(L_{0}-x\right)\right\} / \cosh \left(\omega L_{0}\right)
$$

A similar treatment can be made for $L_{0} \leqslant x \leqslant L$. In the above relations, the maximum speed $U$ is found at $\mathbf{x}=\mathrm{L}_{0}$ and the maximum tensile stress $\sigma_{\max }$ at $x=0$. From (8) and (9), we have

$$
\sigma_{\max }=\left(4 n_{\mathrm{e}^{\omega}} \omega\right)\left\{\left(\mathrm{q} / \omega^{2}-\mathrm{U}_{0}\right)^{2}-\left(\mathrm{q} / \omega^{2}-\mathrm{U}_{\max }\right)^{2}\right\}^{\frac{1}{2}}
$$

A crack will form at $\mathrm{x}=0$, when $\sigma_{\max }$ reaches the tensile strength $T$ of snow. When $T$ is substituted for $\sigma$ Equation (10) gives a relation between $U_{\max }$ and $U_{0}$, where it can be shown that $U_{\max }$ is minimum when $U_{0}=0$. We may call this minimum value the safety limit. The safety limit is plotted against $\theta$ in Figure 3, where the following values were used:

$$
\begin{aligned}
& \eta_{\mathrm{e}}=2.1 \times 10^{5} \mathrm{~N} \mathrm{~m}^{-2} \mathrm{~d}\left(\text { at }-5^{\circ} \mathrm{C},\right. \text { Shinojima 1967); } \\
& \sigma_{\max }=\mathrm{T}=7400 \mathrm{~N} \mathrm{~m}^{-2} \\
& \text { (mean value, McClung 1979); }
\end{aligned}
$$

$$
\rho=300 \mathrm{~kg} \mathrm{~m}^{-3} ; \mu=0.2 ; \lambda=1.0 \mathrm{~d} \mathrm{~m}^{-1}
$$

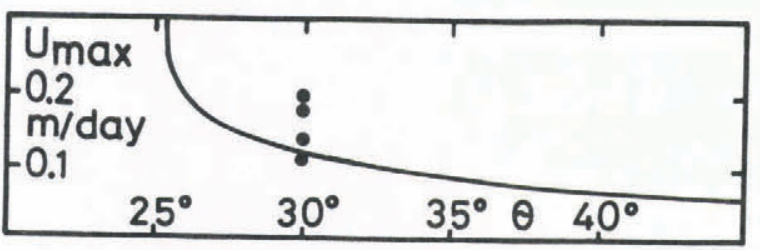

Fig.3. Safety limit of $U_{\max }$ against $\theta$ and observed values just before crack formation.

Solid circles in Figure 3 show the values of $U_{\max }$ measured for 24 hours just before crack formation (Endo 1983), which exceed the safety limit. This supports the validity of the safety limit. Accordingly, if the glide speed is found exceeding the limit at any point, the upstream part must be carefully watched.

\section{CONCLUDING REMARKS}

A unified quantitative explanation is given as to the behavior of a snow cover on a slope covered with bamboo bushes. Particularly, as a result, it is now possible to predict crack formation from data on snow glide. This study has dealt only with bamboo bushes, but the same reasoning can be applied to other bushes and tall grasses.

\section{REFERENCES}

Endo Y 1983 Glide processes of a snow cover as a release mechanism of an avalanche on a slope covered with bamboo bushes. Contributions from the Institute of Low Temperature Science A32: 39-68

McClung D M 1979 In-situ estimates of the tensile strength of snow utilizing large sample sizes. Journal of Glaciology 22(87): 321-329

Shinojima K 1967 Study on the visco-elastic deformation of deposited snow. In Oura $\mathrm{H}$ (ed) Physics of snow and ice, part 2. Sapporo, Institute of Low Temperature Science: $875-907$ 